\title{
Resposta econômica do confinamento de ovinos alimentados com silagens de diferentes cultivares de sorgo
}

\author{
Economic response of feedlot sheep fed silages with different cultivars of sorghum
}

\author{
Ebson Pereira Cândido ${ }^{\mathrm{I}}$ Edson Mauro Santos ${ }^{\mathrm{III}}$ João Paulo de Farias Ramos ${ }^{\mathrm{II}^{*}}$ \\ Juliana Silva de Oliveira ${ }^{\mathrm{II}}$ Ricardo Martins Araújo PinhoII Alexandre Fernandes Perazzo ${ }^{\mathrm{IV}}$ \\ Rosângela Claurênia da Silva Ramos ${ }^{\mathrm{III}}$ Poliane Meire Dias de Freitas ${ }^{\mathrm{IV}}$
}

RESUMO

Objetivou-se com este estudo avaliar o resultado econômico da terminação de ovinos em confinamento, alimentados com silagens de diferentes cultivares de sorgo: 'BRS 810' $e$ 'BRS Ponta Negra' (caráter forrageiro); 'BRS 610' (caráter duplo propósito); e 'BRS 655'e 'BRS 800' (caráter granífero). Utilizaram-se 35 cordeiros, sem padrão racial definido, com idade

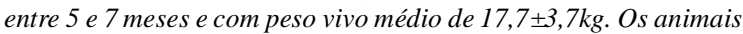
foram mantidos confinados em gaiolas individuais durante 42 dias, sendo abatidos com peso médio de 26,24kg. Utilizou-se um delineamento inteiramente casualizado, com cinco tratamentos (silagem de diferentes cultivares de sorgo) e sete repetições. A relação volumoso:concentrado foi de $48: 52$ (com base na MS), para todas as dietas testadas. $O$ custo médio das silagens foi de 63,$71 ; 71,01 ; 78,99 ; 61,08$ e 63,35 $R \$ t^{-1}$ para as cultivares ' $B R S$ 610', 'BRS 655', 'BRS 800', 'BRS 810'e 'BRS Ponta Negra', respectivamente, promovendo uma receita líquida de 78,34; 78,98; 77,43; 82,23 e 80,57 R\$ carcaça $^{-1}$. A produção de silagem utilizando a variedade 'BRS 810' com caráter forrageiro apresenta menor custo de produção e maior receita líquida por carcaça, além de maior produção de matéria seca por hectare, proporcionando aumentar a capacidade de suporte forrageiro das áreas cultivadas, permitindo confinar maior quantidade de animais.

Palavras-chave: custo de produção, semiárido, Sorghum bicolor.

\section{ABSTRACT}

This study aimed to evaluate the economic result of the termination of feedlot sheep fed silages with different cultivars of sorghum 'BRS 810' and 'BRS Ponta Negra' (forage); 'BRS 610' (dual purpose character) and 'BRS 655' and 'BRS 800' (character grain). Five lambs without defined breed were used, aged between 5 and 7 months, with average weight of $17.7 \pm 3.7 \mathrm{~kg}$. The animals were confined in individual cages for 42 days and slaughtered at an average weight of $26.24 \mathrm{~kg}$. A completely randomized design was used with five treatments (silage of different cultivars of sorghum) and seven repetitions. The forage: concentrate ratio was 48:52 (DM basis) for all diets. The average cost of silage was 63.71, 71.01, 78.99, 61.08 and 63.35 $R \$ t^{1}$ for 'BRS 610', 'BRS 655', 'BRS 800', 'BRS 810' and 'BRS Ponta Negra', respectively promoting a net earnings of 78.34, 78.98, 77.43, 82.23 and 80.57 $R \$$ carcass $^{-1}$. The silage production using the 'BRS 810' with forage purpose has lower production costs and higher net income for carcass. Furthermore higher dry matter production per hectare provided increased support of forage cultivated areas capacity, which allowed greater amount of confined animals.

Key words: production cost, semiarid, Sorghum bicolor.

\section{INTRODUÇÃO}

A análise econômica da produção de ovinos alimentados com silagem de sorgo no semiárido apresenta grande importância, quando se busca identificar as principais restrições a uma melhor organização da cadeia produtiva dos ovinocultores. Isto pode ser explicado pelos seguintes fatores: as particularidades climáticas locais, o nível tecnológico adotado, seleção de genótipos de sorgo inadequados e falta de informações regionais sobre o comportamento agronômico dos materiais genéticos disponíveis e recomendadas para zonas semiáridas (SANTOS et al., 2013).

Assim, a inserção da análise de custos dos processos de conservação de volumosos no contexto

\footnotetext{
'Universidade Federal do Rural da Amazônia (UFAM), Capanema, PA, Brasil.

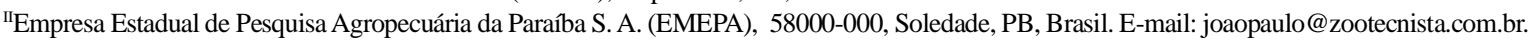
*Autor para correspondência.

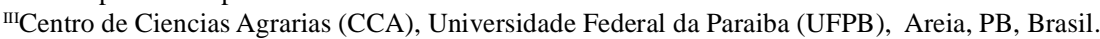

${ }^{\text {IV } U n i v e r s i d a d e ~ F e d e r a l ~ d a ~ B a h i a ~(U F B A), ~ S a l v a d o r, ~ B A, ~ B r a s i l . ~}$ 
do agronegócio é imprescindível para a expansão da sua competitividade no cenário nordestino, tendo em vista que, segundo RESTLE et al. (2007), uma alternativa importante para reduzir os custos com alimentação seria o uso de volumosos produtivos e de elevada qualidade, visando a reduzir os custos com fornecimento de concentrado. Portanto, a aplicação de um sistema de custos simplificado para pequenos produtores permitirá o acompanhamento dos valores e de todas as operações realizadas na produção de diferentes materiais existentes, auxiliando na tomada de decisão a fim de obter lucro e identificar os principais fatores que causam prejuízos.

A produtividade dos diferentes híbridos determina o custo de produção de forragens, por outro lado, o desempenho dos animais alimentados com as silagens desses híbridos determina a receita alcançada nos confinamentos. Sendo assim, tornase de suma importância conhecer a viabilidade econômica de confinamentos baseados nas diferentes cultivares de sorgo utilizadas na região, tomando como base aspectos técnicos de produção, valor nutritivo e desempenho animal.

Nesse contexto, objetivou-se avaliar o custo de produção e o retorno econômico de um sistema de terminação em confinamento de ovinos alimentados com silagem de diferentes cultivares de sorgo.

\section{MATERIAL E MÉTODOS}

O experimento foi conduzido na Estação Experimental de Pendência, pertencente à Empresa Estadual de Pesquisa Agropecuária da Paraíba (EMEPA-PB), localizada no município de Soledade $\mathrm{PB}$, situada nas coordenadas geográficas com latitude de $7^{\circ} 8^{\prime} 18^{\prime \prime} \mathrm{S}$ e $36^{\circ} 27^{\prime} 2^{\prime}$ ' W, com altitude de $534 \mathrm{~m}$ e temperatura média de $30^{\circ} \mathrm{C}$.

$\mathrm{O}$ solo da área experimental apresentou os seguintes atributos químicos (perfil de 0 a 20cm): pH: 6,94; P: 70,38; $\mathrm{K}^{+}: 82\left(\mathrm{mg} \mathrm{dm}^{-3}\right) ; \mathrm{Na}^{+}$: 0,$37 ; \mathrm{H}^{+}+\mathrm{Al}^{+3}: 2,06 ; \mathrm{Al}^{+3}: 0,0 ; \mathrm{Ca}^{+2}: 7,45 ; \mathrm{Mg}^{+2}$ : 2,40 (cmolc $\left.\mathrm{dm}^{-3}\right)$; saturação de bases: $83,51 \%$ e matéria orgânica: $10,55 \mathrm{~g} \mathrm{~kg}^{-1}$.

Efetuou-se a adubação com $50 \mathrm{~kg} \mathrm{ha}^{-1}$ de N, na forma de sulfato de amônio, realizada 15 dias após emergência. A área experimental foi de 0,1ha para cada cultivar de sorgo. Utilizou-se o espaçamento de $0,7 \mathrm{~m}$ entre linhas e uma densidade de semeadura de 12 sementes puras viáveis por metro linear. A colheita foi realizada manualmente e o material transportado em carro de boi, no momento em que os grãos encontravam-se no estado leitoso: pastoso. O material foi picado na forrageira estacionária, homogeneizado e ensilado em tambores de 200 litros.
A seguinte equação foi utilizada para estimar a recuperação de matéria seca: $\mathrm{RMS}=(\mathrm{MFa}$ x MSa)/(MFf x MSf) x 100 onde: RMS: taxa de recuperação de matéria seca (\%); MFa: massa da forragem na abertura $(\mathrm{kg})$; MSa: teor de matéria seca da forragem na abertura (\%); MFf: massa de forragem no fechamento $(\mathrm{kg})$; MSf: teor de matéria seca da forragem no fechamento $(\%)$.

Procedeu-se à colheita de cincolinhas de $1 \mathrm{~m}$ aleatoriamente na área experimental, que formaram uma amostra composta, a qual foi pesada para obter o rendimento de matéria verde; esse, posteriormente, foi convertido em produção de matéria verde por hectare, multiplicando-se a produção por metro linear pelo total de metros lineares em um hectare. Duas plantas foram selecionadas ao acaso para serem secas em estufa de ventilação forçada a $65^{\circ} \mathrm{C}$, até atingirem peso constante, o que possibilitou a estimativa da matéria seca e a conversão de produção de matéria verde em produção de matéria seca. Duas outras plantas foram utilizadas para separação dos componentes lâmina foliar, colmo, material morto e panícula, os quais foram secos na mesma estufa em mesma temperatura, permitindo expressar a proporção dos componentes da planta com base na matéria seca.

O delineamento experimental utilizado foi inteiramente casualizado, com cinco tratamentos e sete repetições. Foram utilizados 35 cordeiros machos, não castrados, sem padrão racial definido (SPRD), com idade entre 5 e 7 meses e com peso vivo médio de $17,7 \pm 3,7 \mathrm{~kg}$. Os animais foram inicialmente vacinados contra clostridioses e everminados contra ecto e endoparasitas e, em seguida, foram distribuídos em gaiolas individuais, medindo $0,80 \times 1,20 \mathrm{~m}$, com livre acesso aos comedouros e bebedouros. $\mathrm{O}$ período de adaptação foi de 11 dias e as pesagens dos animais foram realizadas a cada 14 dias, para controle do desenvolvimento ponderal.

Os alimentos utilizados foram: silagem de sorgo, milho moído, farelo de soja, ureia, cloreto de amônio, calcário e suplemento mineral. Utilizou-se uma dieta completa, com uma relação volumoso:concentrado de 48:52 (base na MS), balanceada, para permitir um ganho de peso médio de $200 \mathrm{~g} \mathrm{dia}^{-1}$, de acordo com as recomendações do NRC (2007). O fornecimento de alimento e de água foi ad libitum. Os animais foram alimentados duas vezes ao dia, às 07h30min e $14 \mathrm{~h} 30 \mathrm{~min}$ e as sobras foram colhidas e pesadas para determinação do consumo e ajuste da ingestão de MS, de forma a permitir $10 \%$ de sobra no cocho.

Os tratamentos experimentais consistiram de cinco dietas contendo silagens de cultivares de sorgo (Tabela 1). Foram avaliadas as seguintes 
Tabela 1 - Composição percentual e químico-bromatológica das dietas experimentais.

\begin{tabular}{|c|c|c|c|c|c|}
\hline & 610 & 655 & 800 & 810 & $\mathrm{PN}$ \\
\hline Ingredientes, \% na MS & \multicolumn{5}{|c|}{ 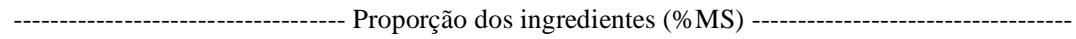 } \\
\hline Silagem & 45,11 & 49,62 & 50,98 & 50,85 & 50,15 \\
\hline Milho & 39,07 & 37,83 & 36,25 & 36,18 & 34,66 \\
\hline Soja & 11,17 & 8,05 & 8,38 & 8,59 & 10,80 \\
\hline Ureia & 0,69 & 0,63 & 0,62 & 0,62 & 0,64 \\
\hline Cloreto de amônio & 1,01 & 0,93 & 0,90 & 0,90 & 0,81 \\
\hline S. mineral ${ }^{2}$ & 2,26 & 2,14 & 2,06 & 2,07 & 2,02 \\
\hline \multirow[t]{2}{*}{ Calcário } & 0,89 & 0,81 & 0,81 & 0,79 & 0,92 \\
\hline & \multicolumn{5}{|c|}{-- Composição Química (\%MS) - } \\
\hline Matéria $\mathrm{Seca}^{3}$ & 38,16 & 41,70 & 40,91 & 40,64 & 39,09 \\
\hline Matéria Orgânica & 89,52 & 90,25 & 90,35 & 90,19 & 90,72 \\
\hline Matéria Mineral & 10,48 & 9,75 & 9,65 & 9,81 & 9,28 \\
\hline Proteína Bruta & 16,54 & 16,61 & 16,40 & 16,71 & 16,29 \\
\hline Fibra em Detergente Neutro ${ }^{4}$ & 29,61 & 28,77 & 29,77 & 29,94 & 32,93 \\
\hline Carboidratos não Fibrosos & 45,17 & 46,91 & 46,73 & 45,37 & 42,30 \\
\hline Carboidratos Totais & 74,78 & 75,69 & 76,51 & 75,32 & 75,23 \\
\hline Extrato Etéreo & 4,54 & 4,79 & 4,06 & 4,91 & 5,27 \\
\hline
\end{tabular}

${ }^{1} 610=$ Silagem de sorgo 'BRS610'; '655' = Silagem de sorgo 'BRS655'; '800' = Silagem de sorgo 'BRS800'; '810' = Silagem de sorgo 'BRS810'; e 'PN' = Silagem de sorgo 'Ponta Negra';

${ }^{2}$ Suplemento mineral (nutriente/kg de suplemento): vitamina A 135.000,00U.I.; Vitamina D3 68.000,00U.I.; vitamina E 450,00U.I.; cálcio 240g; fósforo $71 \mathrm{~g}$; potássio 28,2g; enxofre 20g; magnésio 20g; cobre $400 \mathrm{mg}$; cobalto 30mg; cromo $10 \mathrm{mg}$; ferro $2500 \mathrm{mg}$; iodo $40 \mathrm{mg}$; manganês 1350mg; selênio 15mg; zinco 1700mg; flúor máximo $710 \mathrm{mg}$; Solubilidade do Fósforo(P)em Ácido Cítrico a 2\% (min);

${ }^{3} \%$ com base na matéria natural;

${ }^{4}$ Corrigido para cinzas e proteína;

${ }^{5}$ Isenta de cinzas e proteína.

cultivares na forma de silagem: 'BRS 610'; '655'; '800'; ' 810 'e 'Ponta negra', sendo os quatro primeiros desenvolvidos pelo programa de melhoramento da Embrapa Milho e Sorgo e o último deles pela EMPARN (Empresa de Pesquisa Agropecuária do Rio Grande do Norte). As cultivares possuem as seguintes caracterizações: os híbridos 'BRS 610', 'BRS 655' e a variedade Ponta Negra são forrageiros e os híbridos 'BRS 800' e o 'BRS 810' são de duplo propósito. Todos foram escolhidos por apresentarem potencial produtivo e adaptabilidade à região de estudo, como demonstrado em pesquisas anteriores.

O consumo de MS diário foi obtido pela diferença entre o total de MS ofertada e o total de MS presente nas sobras; o consumo dos nutrientes foi obtido pela diferença entre o total de nutrientes presentes no alimento fornecido e o total de nutrientes presentes na sobra, com base na MS total.

As análises laboratoriais foram realizadas no Laboratório de Nutrição Animal da Universidade Federal da Paraíba, Campus II em Areia - PB, onde foram determinadas, das amostras dos ingredientes da ração e sobras dos animais, as porcentagens de matéria seca (MS), matéria orgânica (MO), matéria mineral $(\mathrm{MM})$, proteína bruta $(\mathrm{PB})$ e extrato etéreo (EE), conforme metodologias citadas por SILVA \& QUEIROZ (2002), e fibra em detergente neutro corrigido para cinzas e proteína (FDNcp), pelo método de VAN SOEST et al. (1991), com modificações propostas pelo manual do aparelho ANKON (ANKON ${ }^{\circledR}$ Technology Corp.), corrigidos para o teor de MM e PB.

Após 42 dias de confinamento, os animais foram submetidos a jejum sólido e dieta hídrica por 16 horas. Decorrido esse tempo, foram pesados para obtenção do peso ao abate. Para calcular a conversão alimentar, dividiu-se a quantidade de matéria seca consumida pelo ganho de peso total e, para obtenção da eficiência alimentar, dividiu-se o ganho de peso total pela quantidade de matéria seca consumida.

$\mathrm{O}$ abate foi procedido em concordância com as normas vigentes do Regulamento de Inspeção Industrial e Sanitária dos Produtos de Origem Animal (BRASIL, 2007). Os animais foram insensibilizados 
por atordoamento com concussão cerebral através de pistola de dardo cativo, seguido de sangria, esfola e evisceração. $\mathrm{O}$ sangue foi recolhido em recipiente previamente tarado, para posterior pesagem.

A análise econômica constou da determinação do custo de estabelecimento e manejo de lavoura e confecção de silagem $\left(\mathrm{R} \$ \mathrm{ha}^{-1}\right)$, custo médio de produção de silagem $\left(\mathrm{R} \$ \mathrm{t}^{-1}\right)$, custo do concentrado $\left(\mathrm{R} \$ \mathrm{t}^{-1}\right)$ e custo diário total da dieta por animal $\left(\mathrm{R} \$ \mathrm{~kg}^{-1}\right)$. No custo total de produção da silagem ( $\left.\mathrm{R} \$ \mathrm{ha}^{-1}\right)$, foram considerados: mecanização, semente de sorgo, tratos culturais, adubo químico, além do custo do processo de colheita das lavouras (corte e transporte) e de ensilagem (confecção do silo e compactação). Todos os preços utilizados nos cálculos foram os praticados no ano de 2012, obtidos por consulta à lista de preços pagos pelo produtor na região adjacente ao município de Campina Grande, PB. Os preços de venda foram estabelecidos com base naqueles praticados na região, sendo $\mathrm{R} \$ 10,00$ o quilo da carcaça inspecionada.

A resposta agronômica das diferentes cultivares de sorgo quanto à produtividade por unidade de área e o valor nutritivo resultante sob a forma de silagem, assim como a avaliação de consumo de alimentos e o desempenho dos ovinos em confinamento, determinaram a lucratividade do sistema, obtido pela receita líquida $\left(R \$\right.$ carcaça $\left.^{-1}\right)$.

Os dados foram submetidos à análise de variância (ANOVA) e, quando necessário, as médias foram comparadas pelo teste de Tukey em nível de $5 \%$ de probabilidade, utilizando-se o programa de análise estatística Sisvar (FERREIRA, 2008).

\section{RESULTADOS E DISCUSSÃO}

A produção de matéria seca foi superior para as cultivares 'BRS 610', 'BRS 810' e 'BRS Ponta Negra', comparado às cultivares 'BRS 655' e 'BRS 800' (Tabela 2). A maior produção de MS reflete na produtividade do sistema de animais confinados, pois proporciona maior número de animais confinados por unidade de área (DALLA CHIEZA et al., 2008). Por outro lado, avaliando as estruturas morfológicas da planta de sorgo, verifica-se que a cultivar 'BRS 810' apresentou maior produção de colmo $\left(18704,09 \mathrm{~kg} \mathrm{ha}^{-1}\right)$, o que a caracteriza como sorgo de propósito forrageiro. As cultivares de sorgo granífero ('BRS 655' e 'BRS 800') e a cultivar de sorgo forrageiro 'BRS 810 ' não diferiram entre si para os teores de $\mathrm{PB}$, sendo superior aos demais, em relação à cultivar 'BRS 610', caracterizada como duplo propósito e 'BRS Ponta Negra' não apresentaram diferenças entre si. Quando materiais com diferenças de precocidade são colhidos em tempo fixo, o teor de PB pode ser afetado pela maior proporção de colmos em relação a folhas, com maior senescência de folhas e material morto naqueles híbridos mais precoces (SKONIESKI et al., 2010).

Observa-se na tabela 3 que não houve diferença significativa para consumo de matéria seca e para as variáveis de desempenho. Dessa forma, a escolha do volumoso na alimentação de ovinos criados no semiárido pode se basear na avaliação econômica. A ingestão de MS foi $36 \%$ superior à estimada pelo NRC (2007) para ovinos com o mesmo peso corporal e ganho de peso desse experimento, fato que pode ser explicado pela boa qualidade das dietas formuladas.

Quando considerada a produção de matéria seca das cultivares 'BRS 810', 'BRS Ponta

Tabela 2 - Produção de matéria seca (MS) das cultivares de sorgo; produção de lâmina, colmo e panícula; porcentagem e produção de proteína bruta (PB); recuperação de MS e produção de MS corrigida.

\begin{tabular}{|c|c|c|c|c|c|}
\hline \multirow{2}{*}{ Variáveis } & \multirow[b]{2}{*}{610} & \multirow[b]{2}{*}{655} & \multirow[b]{2}{*}{800} & \multirow[b]{2}{*}{810} & \multirow[b]{2}{*}{ PN } \\
\hline & & & & & \\
\hline Produção de MS, kg & $14838 \mathrm{a}$ & $10546 b$ & $8455 b$ & $16777 \mathrm{a}$ & $16366 a$ \\
\hline Produção de Lâmina, $\mathrm{kg} \mathrm{ha}^{-1}$ & $2231,48 a$ & $837,37 b$ & $1155,66 \mathrm{~b}$ & $1773,66 \mathrm{a}$ & $2140,02 \mathrm{a}$ \\
\hline Produção de Colmo, $\mathrm{kg} \mathrm{ha}^{-1}$ & $7889,02 \mathrm{c}$ & $6249,62 c$ & $4784,7 \mathrm{c}$ & $18704,1 \mathrm{a}$ & $11790,4 b$ \\
\hline Produção de Panícula, kg ha ${ }^{-1}$ & 3577,54 & 3203,53 & 2306,30 & 2882,50 & 1590,13 \\
\hline Produção de M. Morto, $\mathrm{kg} \mathrm{ha}^{-1}$ & $1140,43 \mathrm{a}$ & $255,27 b$ & $208,11 b$ & $766,36 \mathrm{a}$ & $845,62 \mathrm{a}$ \\
\hline Teor de $\mathrm{PB}^{*}, \%$ & $5,41 \mathrm{~b}$ & $6,94 \mathrm{a}$ & $6,26 \mathrm{a}$ & $6,41 \mathrm{a}$ & $4,91 \mathrm{~b}$ \\
\hline Produção de PB, kg ha ${ }^{-1}$ & 802,74 & 731,89 & 529,28 & 927,77 & 803,57 \\
\hline Recuperação de MS, \% & $82,28 \mathrm{a}$ & $90,40 \mathrm{a}$ & $89,58 \mathrm{a}$ & $77,61 b$ & $75,71 b$ \\
\hline Produção de MSc, kg & $12251 \mathrm{a}$ & $10250 \mathrm{~b}$ & $7957 b$ & $16685 \mathrm{a}$ & $13794 a$ \\
\hline
\end{tabular}

*Teor de PB das cultivares de sorgo antes da ensilagem. 
Tabela 3 - Médias dos parâmetros peso vivo inicial, peso vivo final, ganho de peso diário, consumo de matéria seca diário, conversão alimentar, eficiência alimentar, rendimento e peso de carcaça fria de ovinos em confinamento, terminados com diferentes fontes de volumoso.

\begin{tabular}{|c|c|c|c|c|c|}
\hline \multirow{2}{*}{ Variáveis } & \multirow[b]{2}{*}{610} & \multirow[b]{2}{*}{655} & \multirow[b]{2}{*}{800} & \multirow[b]{2}{*}{810} & \multirow[b]{2}{*}{ PN } \\
\hline & & & & & \\
\hline Peso vivo inicial, $\mathrm{kg}$ & 17,34 & 18,11 & 17,91 & 17,80 & 17,57 \\
\hline Peso vivo final, $\mathrm{kg} \mathrm{ha}^{-1}$ & 25,69 & 26,77 & 26,29 & 26,54 & 25,91 \\
\hline Ganho de peso diário, $\mathrm{g} \mathrm{dia}^{-1}$ & 198,64 & 206,12 & 199,32 & 208,16 & 198,64 \\
\hline Consumo de matéria seca, $\mathrm{g} \mathrm{dia}^{-1}$ & 916,82 & 1005,96 & 1027,66 & 1041,07 & 981,82 \\
\hline Conversão alimentar & 4,66 & 4,92 & 5,23 & 5,07 & 5,02 \\
\hline Eficiência alimentar & 0,22 & 0,20 & 0,20 & 0,20 & 0,20 \\
\hline Rendimento de carcaça fria, $\%$ & 43,24 & 42,51 & 42,91 & 44,15 & 44,06 \\
\hline Peso de carcaça fria, $\mathrm{kg}$ & 11,13 & 11,38 & 11,29 & 11,74 & 11,43 \\
\hline
\end{tabular}

Negra' e 'BRS 610' (16777, 16366 e 14838kg ha ${ }^{-1}$ respectivamente), evidencia-se a potencialidade deste material frente às demais cultivares, mesmo com menor taxa de recuperação de matéria seca $(77,61$ e $75,71 \%)$ após a ensilagem, em relação às demais cultivares (Tabela 2). Considerando-se que as dietas resultaram em mesmo desempenho, o fator produtividade passou a ter uma maior importância na comparação das cultivares.

O custo de implantação e manejo das lavouras das diferentes cultivares de sorgo foi o mesmo, enquanto o custo do processo de colheita e ensilagem variou conforme a produção de matéria seca corrigida (Tabela 2). Resultado semelhante também foi observado por NEUMANN et al. (2002), os quais demonstraram em seu estudo que híbridos de caráter forrageiro apresentaram menor custo de produção condicionada pela maior produção por hectare. Logo, o custo da silagem apresentou valores variando de 61,08 a 78,99 $\mathrm{R} \$ \mathrm{t}^{-1}$, enquanto o custo do concentrado praticamente foi similar entre os tratamentos, com valores variando de 1180,89 a 1184,19 R\$ t-1 (Tabela 4).

$O$ custo por tonelada de matéria seca da silagem produzida foi menor para 'BRS 810' (227,85 $\mathrm{R} \$ \mathrm{t}^{-1}$ ), devido às maiores produções de $\mathrm{MS} / \mathrm{ha}$, diluindo, dessa forma, o valor por $\mathrm{kg}$ do volumoso produzido, aliado à maior produtividade de $\mathrm{PB}$ $\left(927,77 \mathrm{t} \mathrm{ha}^{-1}\right)$, o que pode reduzir os custos com concentrados proteicos no balanceamento de dietas, usando essa cultivar como forma de volumoso. Já o 'BRS 800' apresentou o maior custo de produção por

Tabela 4 - Apreciação econômica do sistema produtivo.

\begin{tabular}{|c|c|c|c|c|c|}
\hline \multirow{2}{*}{ Itens } & \multirow[b]{2}{*}{610} & \multirow[b]{2}{*}{655} & \multirow[b]{2}{*}{800} & \multirow[b]{2}{*}{810} & \multirow[b]{2}{*}{$\mathrm{PN}$} \\
\hline & & & & & \\
\hline Custo da lavoura (implantação + manejo), $\mathrm{R} \$ \mathrm{ha}^{-1}$ & 373 & 373 & 373 & 373 & 373 \\
\hline Custo da lavoura (colheita + ensilagem), $\mathrm{R} \$ \mathrm{ha}^{-1}$ & 3129,91 & 2576,16 & 2215,31 & 3428,75 & 3167,18 \\
\hline Custo total da lavoura, $\mathrm{R} \$ \mathrm{ha}^{-1}$ & 3502,98 & 2949,16 & 2588,31 & 3801,75 & 3540,18 \\
\hline Custo da silagem, $\mathrm{R} \$ \mathrm{t}^{-1} *$ & 63,71 & 71,01 & 78,99 & 61,08 & 63,35 \\
\hline Custo da MS da silagem, $\mathrm{R} \$ \mathrm{t}^{-1}$ & 285,93 & 287,72 & 325,29 & 227,85 & 256,65 \\
\hline Custo da PB produzida, $\mathrm{R} \$ \mathrm{t}^{-1}$ & 1297,58 & 1312,54 & 1138,13 & 975,78 & 988,25 \\
\hline Custo do concentrado, $\mathrm{R} \$ \mathrm{t}^{-1}$ & 1180,89 & 1181,84 & 1183,13 & 1184,19 & 1181,42 \\
\hline Custo da MS do concentrado, $\mathrm{R} \$ \mathrm{t}^{-1}$ & 1235,89 & 1236,88 & 1238,23 & 1239,34 & 1236,35 \\
\hline Consumo silagem, $\mathrm{kg} \mathrm{dia}^{-1}$ & 1,771 & 2,154 & 2,378 & 2,505 & 2,365 \\
\hline Consumo concentrado, $\mathrm{kg} \mathrm{dia}^{-1}$ & 0,569 & 0,572 & 0,555 & 0,578 & 0,553 \\
\hline Custo silagem, $\mathrm{R} \$$ animal $^{-1} \mathrm{dia}^{-1}$ & 0,11 & 0,15 & 0,19 & 0,15 & 0,15 \\
\hline Custo concentrado, $\mathrm{R} \$$ animal $^{-1} \mathrm{dia}^{-1}$ & 0.67 & 0.68 & 0.66 & 0.68 & 0.65 \\
\hline Custo total da dieta, $\mathrm{R} \$$ animal $^{-1} \mathrm{dia}^{-1}$ & 0,78 & 0,83 & 0,84 & 0,84 & 0,80 \\
\hline Receita bruta, $\mathrm{R} \$$ carcaça $^{-1}$ & 111,30 & 113,80 & 112,90 & 117,40 & 114,30 \\
\hline Receita líquida, $\mathrm{R} \$$ carcaça $^{-1}$ & 78,34 & 78,98 & 77,43 & 82,23 & 80,57 \\
\hline
\end{tabular}


tonelada de MS (325,29 R \$ t $\left.\mathrm{t}^{-1}\right)$, enquanto o 'BRS 610' e 'BRS 655' exibiram custos semelhantes $(285,93$ e $287,72 \mathrm{R} \$ \mathrm{t}^{-1}$, respectivamente).

A economicidade do sistema de criação de ovinos no Semiárido está atrelada à produção e utilização de volumosos, já que implica a quantidade de concentrado a ser fornecida. Segundo BRONDANI et al. (2000), essa melhoria pode ser obtida através do uso de volumosos com alto valor nutritivo e baixo custo de produção, os quais diluem sensivelmente os custos da alimentação, concordando com os resultados obtidos no presente trabalho.

O gasto diário com alimentação foi de $\mathrm{R} \$$ 0,$78 ; 0,83 ; 0,84 ; 0,84$ e 0,80 , respectivamente, para as dietas que continham silagem de sorgo 'BRS 610', 'BRS 655', 'BRS 800', 'BRS 810' e 'BRS Ponta Negra', respectivamente. As cultivares 'BRS 800' e 'BRS 810' apresentaram os maiores gastos diários com alimentação, o que se deve ao maior consumo numérico de matéria seca. Fatores climáticos, o nível de tecnologia dominado pelo produtor, a facilidade de obtenção de mão-de-obra, aspectos de mercado e localização da propriedade certamente serão fatores a provocar variação nos custos dos volumosos e dos concentrados empregados no confinamento(BARROS et al., 2010). O preço pago por kg de carcaça no abate dos animais desse experimento foi de $10 \mathrm{R} \$ \mathrm{~kg}^{-1}$.

Observa-se que os ovinos alimentados com a silagem da cultivar 'BRS 810' apresentaram a melhor receita líquida por carcaça, deduzindo o custo de alimentação (82,23 R \$ carcaça $\left.{ }^{-1}\right)$, valor esse pouco expressivo em relação aos demais tratamentos. No entanto, quando se considera o acréscimo no efetivo de ovinos criados por hectare, proporcionado pela maior produção de matéria seca corrigida, repercute em maior escala de produção, tornando mas viável economicamente para o produtor. Essas diferenças são importantes para ressaltar a escolha da cultivar de sorgo a ser utilizada no processo de ensilagem no semiárido, pois, mesmo não havendo diferenças significativas de consumo e desempenho de ovinos alimentados com as cultivares analisadas, a escolha se dará em função do menor custo por $\mathrm{kg} \mathrm{MS}^{-1}$ de silagem, bem como a maior produtividade por hectare, o que reflete na maior quantidade de animais confinados por área, mostrando que a estratégia correta em decisões de investimento é fundamental para um bom resultado.

Além disso, fica claro que as cultivares de caráter mais forrageiro são mais indicadas para o confinamento de ovinos, pois mantêm o desempenho dos animais, além de serem mais produtivas, resultando em maior eficiência econômica no confinamento, contrariando recomendações anteriores de que seria mais interessante a utilização de silagens de sorgo granífero. Sendo assim, o uso de cultivares mais produtivas também pode permitir um aumento no número de animais confinados, o que pode também melhorar a eficiência dos sistemas de produção do Semiárido Brasileiro.

\section{CONCLUSÃO}

A produção de silagem utilizando a variedade 'BRS 810' com caráter forrageiro apresenta menor custo de produção e maior receita líquida por carcaça, em função da maior produção de matéria seca por hectare, proporcionando aumento da capacidade de suporte forrageiro das áreas cultivadas, permitindo confinar maior quantidade de animais. Dessa forma, esse híbrido deve ser recomendado para a terminação de ovinos em confinamento nas condições em que se conduziu essa pesquisa.

\section{COMITÊ DE ÉTICA E BIOSSEGURANÇA}

\section{Declaração dos autores}

Nós autores do artigo intitulado "Resposta econômica do confinamento de ovinos, alimentados com silagens de diferentes cultivares de sorgo" declaramos, para os devidos fins, que o projeto que deu origem aos dados deste não foi submetido para avaliação ao Comitê de Ética da Universidade "UNIVERSIDADE FEDERAL DA PARAIBA", mas estamos cientes do conteúdo das resoluções do Conselho Nacional de Controle de Experimentação Animal - CONCEA <http://www.mct.gov.br/index.php/content/ view/310553.html > caso envolva animais.

Dessa forma, os autores assumem total responsabilidade pelos dados apresentados e estão disponíveis para possíveis questionamentos, caso venham a ser requeridos pelos órgãos competentes.

\section{REFERÊNCIAS}

BARROS, R.C. et al. Viabilidade econômica da substituição da silagem de sorgo por cana-de-açúcar ou bagaço de cana amonizado com ureia no confinamento de bovinos. Revista Brasileira de Saúde e Produção Animal, Salvador, v.11, n.3, p.555-569, 2010. Disponível em: <http://revistas.ufba.br/index.php/rbspa/article/ view/1730/991>. Acesso em: 12 jan. 2014.

BRASIL. MINISTÉRIO DA AGRICULTURA PECUÁRIA E ABASTECIMENTO. Regulamento da Inspeção industrial e Sanitária deProdutos de OrigemAnimal. Brasília, DF: 2007. 252p.

BRONDANI, I.L. et al. Silagem de alta qualidade para bovinos. In: RESTLE, J. (Ed.). Eficiência na produção de bovinos de corte. Santa Maria: UFSM, 2000. p.185-204.

DALLA CHIEZA, E. et al. Aspectos agronômicos de híbridos de sorgo (Sorghum bicolor L. Moench) no desempenho e economicidade de novilhos confinados. Acta Scientiarum. Animal Sciences, Maringá, v.30, n.1, p.67-73, 2008. Disponível em: <http://eduem.uem.br/ojs/index.php/ActaSciAnimSci/article/ viewFile/3613/2668>. Acesso em: 15 jan. 2014.

Ciência Rural, v.45, n.1, jan, 2015. 
FERREIRA, D.F. SISVAR: um programa para análises e ensino de estatística. Revista Symposium. Lavras, v.6, p.36-41, 2008.

NRC. (NATIONAL RESEARCH COUNCIL). Nutrients requeriments of small ruminants. Washington, D.C.: National Academy, 2007. 362p

NEUMANN, M. et al. Avaliação do valor nutritivo da planta de silagem de diferentes híbridos de sorgo (Sorghum bicolor L. Moench). Revista Brasileira de Zootecnia, Viçosa, v.31, n.1, p.293-301, 2002. Disponível em: <http://www.scielo.br/scielo. php? script $=$ sci_arttext $\&$ pid $=S 1516-35982002000200002>$. Acesso em: 20 jan. 2014. doi: http://dx.doi.org/10.1590/S151635982002000200002 .

RESTLE, J. et al. Apreciação econômica da terminação em confinamento de novilhos Red Angus superjovens abatidos com diferentes pesos. Revista Brasileira de Zootecnia, Viçosa, v.36, n.04,p.978-986, 2007. Disponívelem: <http://www.scielo.br/scielo. php?script=sci_arttext $\&$ pid $=$ S1516-35982007000400030\&lng=en $\& n r m=i s o \& t \operatorname{lng}=p t \#>$. Acesso em: 25 jan. 2014. doi: http://dx.doi. org/10.1590/S1516-35982007000400030.
SANTOS, R.D. et al. Agronomic characteristics of forage sorghum cultivars for silage production in the lower middle San Francisco Valley. Acta Scientiarum. Animal Sciences, Maringá, v.35, n.1, p.13-19, 2013. Disponível em: <http://www.scielo. br/scielo.php? pid $=$ S 1807-86722013000100003\&script $=$ sci arttext>. Acesso em 27 jan. 2014. doi: http://dx.doi.org/10.4025/ actascianimsci.v35i1.13072

SILVA, D.J.; QUEIROZ, A.C. Análises de alimentos (métodos químicos e biológicos). 3.ed. Viçosa, MG: UFV, 2002. 235p.

SKONIESKI, F. R., et al. Produção, caracterização nutricional e fermentativa de silagens de sorgo forrageiro e sorgo duplo propósito. Acta Scientiarum. Animal Sciences, Maringá, v.32, n.1, p.27-32, 2010. Disponível em: <http://periodicos.uem.br/ojs/ index.php/ActaSciAnimSci/article/view/7200>. Acesso em 29 jan. 2014. doi: $10.4025 /$ actascianimsci.v32i1.7200

Van SOEST, P.J.; ROBERTSON, J.B.; LEWIS, B.A. Methods for dietary fiber, neutral detergent fiber, and nonstarch polysaccharides in relation to animal nutrition. Journal of Dairy Science, v.74, n.10, p.3583-3597, 1991. 